\title{
EDITORIAL
}

\section{Missão cumprida!}

Renata Rodrigues Teixeira de Castro e Antonio Claudio Lucas da Nóbrega

Neste número encerramos nosso trabalho como editores da RBME. Participando do conselho editorial deste periódico desde 2000, passamos por diferentes cargos, como os de assistente editorial, editora associada e editora-chefe (RRTC) e editor associado, editor-chefe e editor sênior (ACLN). A decisão de deixarmos os cargos atuais foi motivada por nossa percepção de que é necessário permitir a renovação das diretrizes editoriais da RBME e também pelo desejo de buscarmos outros desafios. Em outras palavras: encerrou-se um ciclo para a RBME e para nós. O trabalho de editor é, ao mesmo tempo, extenuante e gratificante. O desafio de capitanear um periódico científico em nosso país mostra-se instigante, com prazer de vitória a cada meta alcançada. Dessa forma, um balanço das conquistas, e também dos inevitáveis fracassos, é importante para que possamos avaliar o trabalho desenvolvido e auxiliar aqueles que passam a dirigir a RBME.

Nesse período de praticamente oito anos, nos deparamos com dificuldades financeiras e com a ausência de uma estrutura mínima para gerenciar o periódico. Tínhamos a sensação de ter que "trocar o pneu com o carro andando"! Partindo desse diagnóstico, uma das nossas prioridades foi estabelecer uma rotina de preparação de projetos para captação de patrocínios privados e das agências de fomento. Passamos, então, a contar com o fluxo de recursos limitados, mas indispensáveis, da CAPES, CNPq, Ministério do Esporte e diversas empresas. Paralelamente, desenvolvemos um sistema de gerenciamento editorial via internet em parceria com uma empresa nacional e atualmente estamos em fase final de construção de um sistema próprio com apoio do CNPq e da Universidade Federal Fluminense. Enquanto viabilizávamos financeiramente o periódico, definimos a política editorial tendo como eixo central estabelecer a RBME como um instrumento de publicação prioritária de artigos originais, tanto de estudos clínicos aplicados quanto de pesquisas básicas e experimentais. Essa era uma tarefa muito difícil, mas necessária, pois, ao mesmo tempo em que fortalecíamos o perfil acadêmico e científico do periódico, mantínhamos o interesse do profissional de nossa especialidade a quem servimos enquanto sociedade médica. Uma vez garantida a saúde financeira do periódico e estabelecida a meta a alcançar, partimos para construir o elemento intermediário que funciona como o mecanismo central dos periódicos de impacto internacional: aumentar o corpo de revisores qualificados e elevar a qualidade e a quantidade dos artigos submetidos. A implantação de um sistema eletrônico para gerenciamento da submissão e revisão dos artigos e a conquista da indexação em diferentes bases de dados conferiram à RBME o selo de qualidade que acabou por atrair um número crescente de pesquisadores, estimulando o ciclo virtuoso: aumento da qualidade - aumento das submissões - maior seletividade - aumento da qualidade. Ao assumirmos a RBME, o número de artigos submetidos era muito pequeno (cerca de 32/ano). Ao longo desses anos, o aumento da visibilidade da RBME aumentou exponencialmente o número de submissões (cerca de 290/ano) e, apesar de termos também elevado o número de artigos publicados por fascículo, fomos obrigados a aumentar o número de recusas, mesmo de artigos com qualidade, que atualmente transita em torno de $54 \%$.

Apesar de contarmos com uma poderosa ferramenta eletrônica para gerenciamento das submissões, o enorme número de artigos submetidos anualmente ultrapassa a capacidade de trabalho voluntário do corpo editorial. Assim, muitas vezes, o tempo decorrido entre submissão e a primeira resposta enviada aos autores é maior do que o desejável. Ainda há muito que melhorar sob esse aspecto. O crescimento da RBME nos levou a um caminho inevitável: a Sociedade Brasileira de Medicina do Exercício e do Esporte (SBME) deve considerar seriamente profissionalizar as funções de editores e equipe, a exemplo do que ocorreu recentemente com os Arquivos Brasileiros de Cardiologia. Não é mais possível que o maior periódico científico de ciências do exercício e do esporte da América Latina continue crescendo sem oferecer as condições de trabalho e, assim, garantir a dedicação necessária dos ocupantes dos seus cargos principais.

Finalizamos este editorial com a satisfação de termos contribuído para o crescimento da RBME, que hoje é um periódico conhecido por qualquer estudante ou profissional interessado em medicina do esporte e ciências do exercício em nosso país. Inicia-se um novo ciclo. Nossa avaliação é a de que o primeiro passo deve ser a definição do caminho a seguir, pois somente será possível escolher o método e os instrumentos de trabalho se soubermos onde pretendemos chegar. Assim, desejamos sucesso à equipe que nos sucede e agradecemos o apoio da SBME, de todos os membros do conselho editorial e revisores ad-hoc e de nossos editores associados, Profa. Dra. Kelb Bousquet-Santos e Prof. Dr. Marcos Doderlein Polito, bem como dos patrocinadores e leitores. Saudações desportivas! 